\title{
Strengthening Of Subgrade by Using RBI Grade-81 A Case Study.
}

\author{
Er. Tejinder Singh \& Er. Navjot Riar \\ 1 Assistant Professor, Civil Engineering Department, Chandigarh University, Gharuan, Mohali-Punjab. \\ 2 Research Assistant, Environment Health \& Safety Department, Vardhman Textile Ltd., Ludhiana-Punjab.
}

\begin{abstract}
Road infrastructure in India is developing at a very fast pace. A good pavement is needed for the safe, comfortable and economical movement of traffic. If the in situ soil has no adequate strength, either soil from other sites are to be used or the available soil has to be stabilized so that it attains sufficient strength to carry the traffic load. Soil can be stabilized with RBI grade 81 and then can be used in Sub grade and also as Sub base and base Layers. The whole Pavement can be constructed by using RBI grade 81 thus reducing energy consumed and placing of unbound granular material (WBM/WMM) without compromising on Strength and durability. Various samples have been made by taking soil with 0\% RBI Grade-81 content; 2\% RBI Grade-81 content; 4\% RBI Grade-81 content; 6\% RBI Grade-81 content; $8 \%$ RBI Grade-81. The CBR sample is prepared by 7 days curing and 4 days soaked period. The comparison of the strength results with or without RBI Grade 81 has been done. It has been found that RBI Grade 81 is a unique and innovative material which results in saving the extra cost of the pavement.
\end{abstract}

Keywords: RBI Grade 81, subgrade, stabilization, CBR value.

\section{Introduction}

In developing countries like India the biggest handicap to provide a complete net work of road system is the limited finances available to build road by the conventional methods. Therefore there is a need to resort to one of the suitable methods of low cost road construction to meet the growing needs of the road traffic. The construction cost can be considerably decreased by selecting local materials including local soils for the construction of the lower layers of the pavement such as the sub-base course. Soil stabilization is the alteration of the property of a locally available soil to improve its engineering performance, such as strength, stiffness, compressibility, permeability, workability, and sensitivity.

The several reasons for using stabilization are Poor sub grade conditions, Borderline base materials, Construction of superior bases, Moisture control, Dust control and Salvaging old roads. The uses of stabilization are Economical road construction, Upgrading of road, Maintenance of unpaved roads, Rehabilitation of failed roads, Construction of roads, parking areas, Air strips,

Mass fills. Soils could be stabilized by mechanical, chemical, electrical, or thermal means. Chemical stabilization includes the addition of RBI Grade 81, cement, lime, asphalt, chemical compounds, or a combination of those.

RBI Grade 81(Road Building International Grade 81) is a unique and innovative product that was developed for the stabilization of a wide spectrum of soils in an efficient, least- cost manner. RBI Grade 81 is an environmentally friendly, inorganic, hydration activated powder based stabilizer that reacts with soil particles to create layers that are interconnected through a complex inter particle framework. RBI Grade 81 is a combination of naturally occurring compounds. Road can be opened to traffic within 24 hours of final compaction. It provides a dust free surface. If the nature of the soil changes for different depths, most of the methods for stabilization cannot be used. RBI Grade 81 has a wide range of response spectrum. Response spectrum is the range of soils for which a particular stabilizer can be used.

Ajith (1993) [1] studied the effect of using fly ash and lime on red soil. The optimum value of additive combination was found to be $15 \%$ fly ash and 5\% lime. Gaulkar (1999) [2] investigated the effect of using lime as stabilizing agent on black cotton soil. He found that, by adding $4 \%$ to $6 \%$ of lime to black cotton soil, the soaked CBR increased considerably. Biju (2003) [3] studied about the use of TerraZyme for pavement subgrade stabilization. TerraZyme is one of the bio-enzyme stabilizers used for stabilizing the soil. This method was found to be most effective for soils containing larger percent of silt. Kunal (2006) [4] investigated the effect of using cement as stabilizing agent on two different types of sands A \& sand B. The optimum value of cement was found to be 3\% for rural roads. Mithra, et al., (2009),[5] study was undertaken with the objective to find the fast pavement construction technology using in-situ soil by stabilization with a natural soil stabilizer "RBI Grade 81". For the study, a stretch constructed on Reasi Pauni Road, Jammu is taken into consideration. Atterberg's Limits, Compaction, CBR, tests were conducted on soil samples with different percentages of RBI 81 with 0\% to 8\%. VENU GOPAL.N; (2009),[6] Studied of soil Properties With Silica fume As Stabilizer And 
Comparing The same With Rbi-81 And Cost Estimation The laboratory investigations indicate the soil samples have low strength. In order to improve the strength of native soil, the soil samples were treated by varying Silica Fume and RBI- 81 grade content in the range of $1 \%$ to $4 \%$ by weight. The treated soil samples were subjected to triaxial compression test to determine strength of soil.

\section{Materials For Study}

A. Soil: The soil sample selected is obtained from link road of village Manakwal to village Dhandra, Dist. Ludhiana Punjab and the following tests are conducted on the soil sample. The soil contains $32.5 \%$ sand, $67.5 \%$ silt \& clay.

B. RBI Grade-81: RBI Grade 81 is a powder that is composed of a number of naturally occurring compounds. It is odourless, the $\mathrm{pH}$ of saturated paste is 12.5 . It improves the structural properties of a wide range of soils. It is particularly effective with silty-clayey soil with low geo-mechanical qualities. RBI Grade 81 works by hydration reaction. Pore space is filled by a crystalline growth. An irreversible interparticle matrix is formed. Through the addition of low dosages of RBI Grade 81 the volume stability of the soil is increased significantly. The reaction of RBI Grade 81 with soil particles produces as an inter-particle matrix that binds soil particles together into a rigid mass. This binding of the soil particle, through both chemical bonds and frictional forces, serves to limit the pore volume of the created rigid stabilized soil system.

RBI Grade 81 is insoluble in water, non UV degradable, inert and chemically stable. It forms a dust free surface and is simple to apply and hardens fast. It is durable and permanent. It is environmental friendly and aesthetically pleasing. Strength of soil treated with RBI Grade 81 increases with age. It gains strength till about one year after application to soil.

Permeability of soil mass decreases with addition of RBI Grade 81 as they reduces pore spaces. The use of RBI Grade 81 does not produce expansive salts when used in soils with clay content. Hence they do not cause cracks due to volume change. RBI Grade 81 converts clay irreversibly into cementitious calcium silicate and aluminum hydrates. RBI Grade 81 creates a volume stable layer with very small capillary spaces. The stabilized soil is bound into an irreversible matrix where cracking is highly improbable. Hence maintenance costs are low or non-existent for roads constructed using RBI Grade 81.

\section{PROPERTIES OF RBI GRADE 81}

\begin{tabular}{|l|l|}
\hline \multicolumn{2}{|c|}{ CHEMICAL COMPOSITION $^{[9]}$} \\
\hline \multicolumn{2}{|c|}{ POWDER } \\
\hline PROPERTIES & \% BY MASS \\
\hline $\mathrm{Ca}$ & $\mathrm{Cao} 52-56$ \\
\hline $\mathrm{Si}$ & $\mathrm{Sio}_{2} 15-19$ \\
\hline $\mathrm{S}$ & $\mathrm{So}_{3} 9-11$ \\
\hline $\mathrm{Al}$ & $\mathrm{Al}_{2} \mathrm{O}_{3} 5-7$ \\
\hline $\mathrm{Fe}$ & $\mathrm{Fe}_{2} \mathrm{O}_{3} 0-2$ \\
\hline $\mathrm{Mg}$ & $\mathrm{MgO}_{0} 0-1$ \\
\hline $\mathrm{Mn}, \mathrm{k}, \mathrm{Cu}, \mathrm{Zn}$ & $\mathrm{Mn}+\mathrm{K}+\mathrm{Cu}+\mathrm{Zn} 0,10,3$ \\
\hline $\mathrm{H}_{2} \mathrm{O}$ & $1-3$ \\
\hline Fiber (Polypropylene) & $0-1$ \\
\hline Additives & $0-4$ \\
\hline
\end{tabular}

\section{Experimental Investigations}

Wet sieve analysis was done for determining particle size distribution. This gives only the particle size distribution up to that retained on 75 micron sieve. For further classification of soil to silt and clay, hydrometer analysis was done. Grain size distribution curves of soil are shown in Fig. 1. Liquid limit (LL) and plastic limit (PL) tests were conducted as per IS specifications for studying the effects of different percentages of RBI Grade 81 on index properties of soil. Plasticity index (PI) was calculated from these values. Variations of LL, PL and PI of soil are shown in Table1. To determine the maximum dry density and corresponding optimum moisture content, modified Proctor compaction tests were conducted. Modified Proctor test as per IS 2720 (partVIII) was conducted on soil with different percentages of RBI Grade 81. Change in optimum moisture content (OMC) and maximum dry density (MDD) of soil are shown in Table1.

The CBR specimen were prepared with different percentages RBI Grade $81(0 \%, 2 \%, 4 \%, 6 \%$ and $8 \%$ ) was done as per IS specifications. A water content of $1 \%+\mathrm{OMC}$ was added for preparation of specimen. This was to make good the loss of water during mixing. CBR test at 7 days were conducted after curing the specimen. Curing was 
Strengthening Of Subgrade By Using Rbi Grade- 81 A Case Study.

done by covering the specimen with a wet cotton cloth for maintaining the OMC. CBR test at 11 days was done after soaking for 4 days, the sample which has been cured for 7 days. This was considered as soaked CBR in the case of soil specimens with RBI Grade 81. The variation in CBR values of soil are shown in Tables1.

Table 1: Soil Test Results

\begin{tabular}{|c|c|c|c|c|c|c|}
\hline & \multicolumn{3}{|c|}{ ATTERBERG'S LIMITS } & OMC & MDD & CBR (7 DAYS CURED \\
\hline (\%) & $\begin{array}{l}\text { LL } \\
(\%)\end{array}$ & $\begin{array}{c}\text { PL } \\
(\%)\end{array}$ & $\begin{array}{c}\text { PI } \\
(\%)\end{array}$ & (\%) & g/cc & (\%) \\
\hline 0 & 33.67 & 24.47 & 9.2 & 9.4 & 1.93 & 2.14 \\
\hline 2 & 33.5 & 24.50 & 9 & 8.95 & 1.92 & 28.9 \\
\hline 4 & 32.4 & 24.70 & 7.7 & 9.67 & 1.90 & 60.82 \\
\hline 6 & 31.5 & 25.50 & 6 & 11 & 1.88 & 105.01 \\
\hline 8 & 30.8 & 26.10 & 4.7 & 12.05 & 1.87 & 135.50 \\
\hline
\end{tabular}

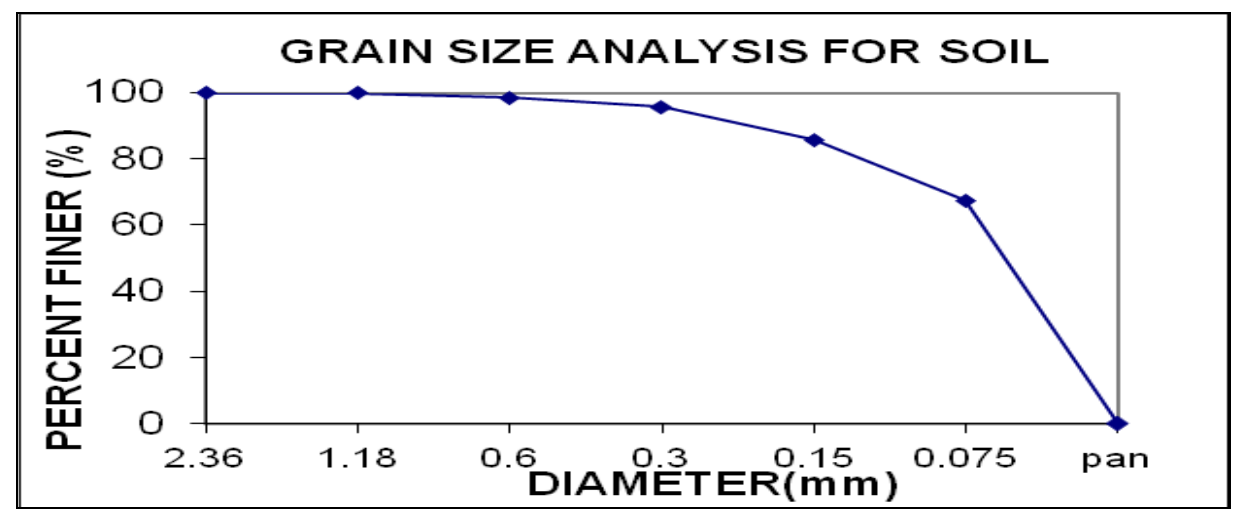

Fig 1: Grain Size Distribution

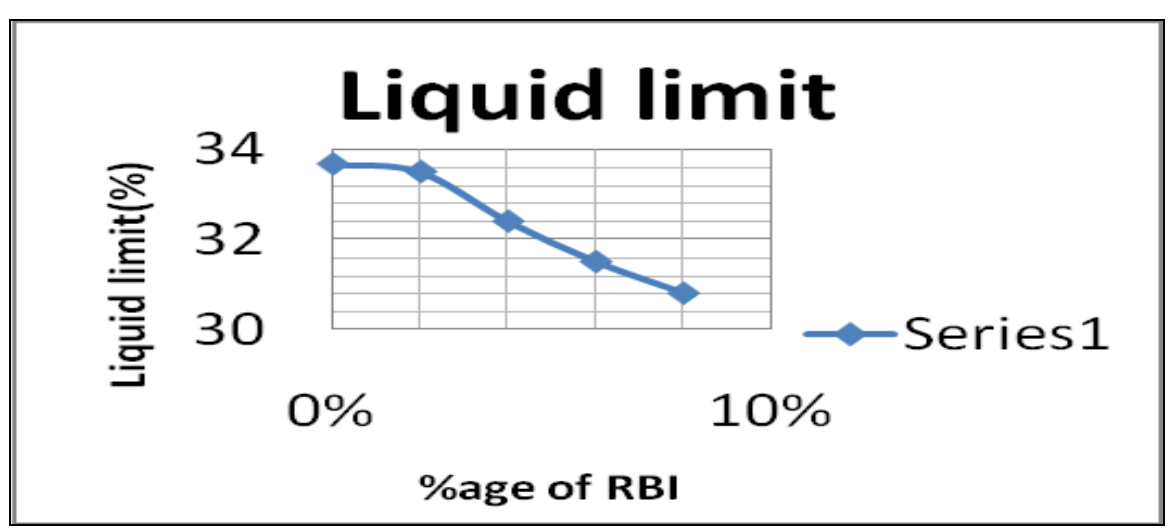

Fig 2: Liquid limit for soil with different \% of RBI Grade 81 


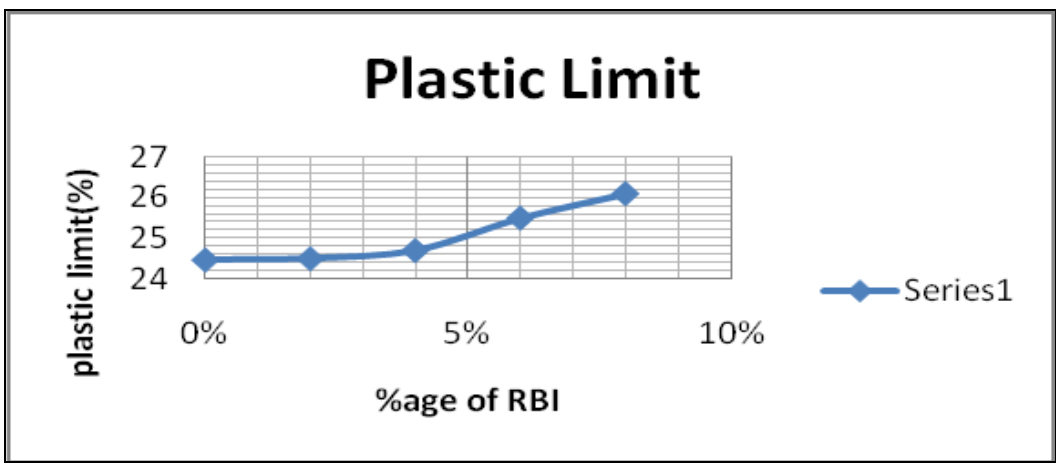

Fig 3: Plastic limit for soil with different $\%$ of RBI Grade 81

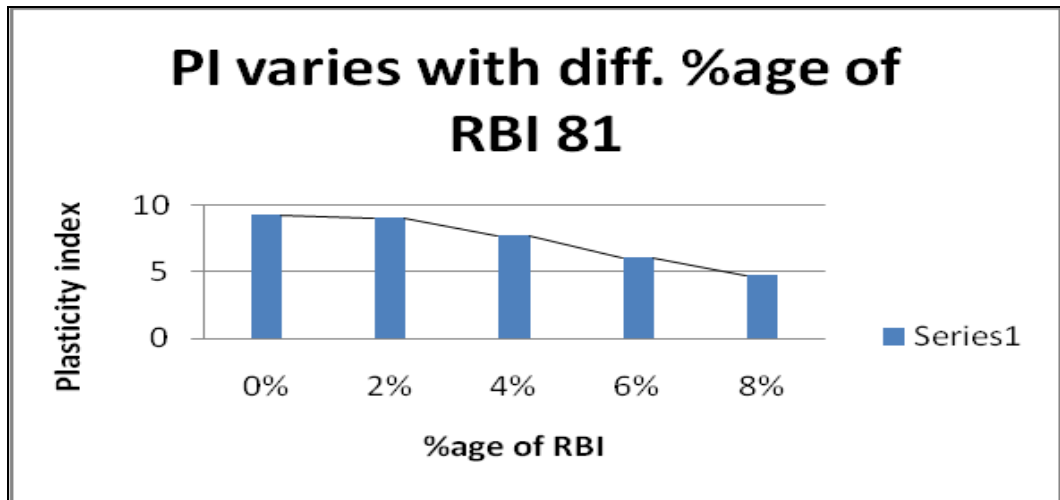

Fig 4: Plasticity Index for soil with different $\%$ of RBI Grade 81

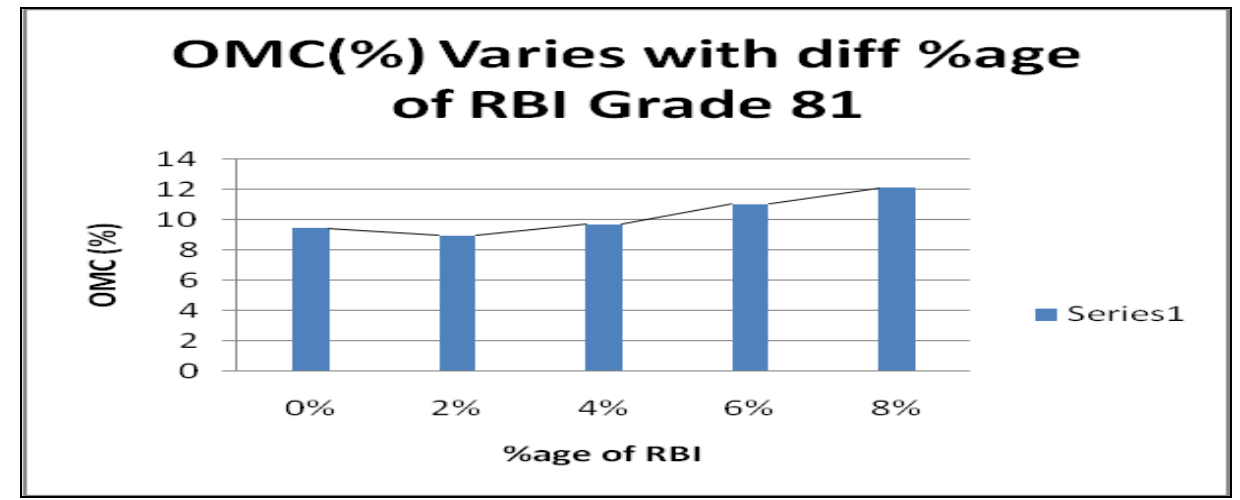

Fig 5: Result for OMC

\begin{tabular}{|c|c|c|c|c|c|c|}
\hline S.No. & Description & \multicolumn{5}{|c|}{$\begin{array}{c}\text { Pavement thickness required above Sub grade(in cm) for } \\
\text { following CBR Values(for 7 days cured and 4 days Soaked } \\
\text { Conditions) }\end{array}$} \\
\hline 1 & CBR & $2.14 \%$ & $28.9 \%$ & $60.82 \%$ & $105.01 \%$ & $135.5 \%$ \\
\hline 2 & $\begin{array}{c}\text { Soil + \% of } \\
\text { RBI 81 }\end{array}$ & $\begin{array}{c}\text { Soil + 0\% } \\
\text { RBI 81 }\end{array}$ & $\begin{array}{c}\text { Soil + } \\
2 \% \\
\text { RBI } 81\end{array}$ & $\begin{array}{c}\text { Soil }+4 \% \\
\text { RBI } 81\end{array}$ & $\begin{array}{c}\text { Soil }+6 \% \\
\text { RBI } 81\end{array}$ & $\begin{array}{c}\text { Soil }+8 \% \\
\text { RBI } 81\end{array}$ \\
\hline 3 & $\begin{array}{c}\text { CBR } \\
\text { Design } \\
\text { Curve C }\end{array}$ & 57 & 15 & 15 & 7.5 & 7.5 \\
\hline
\end{tabular}



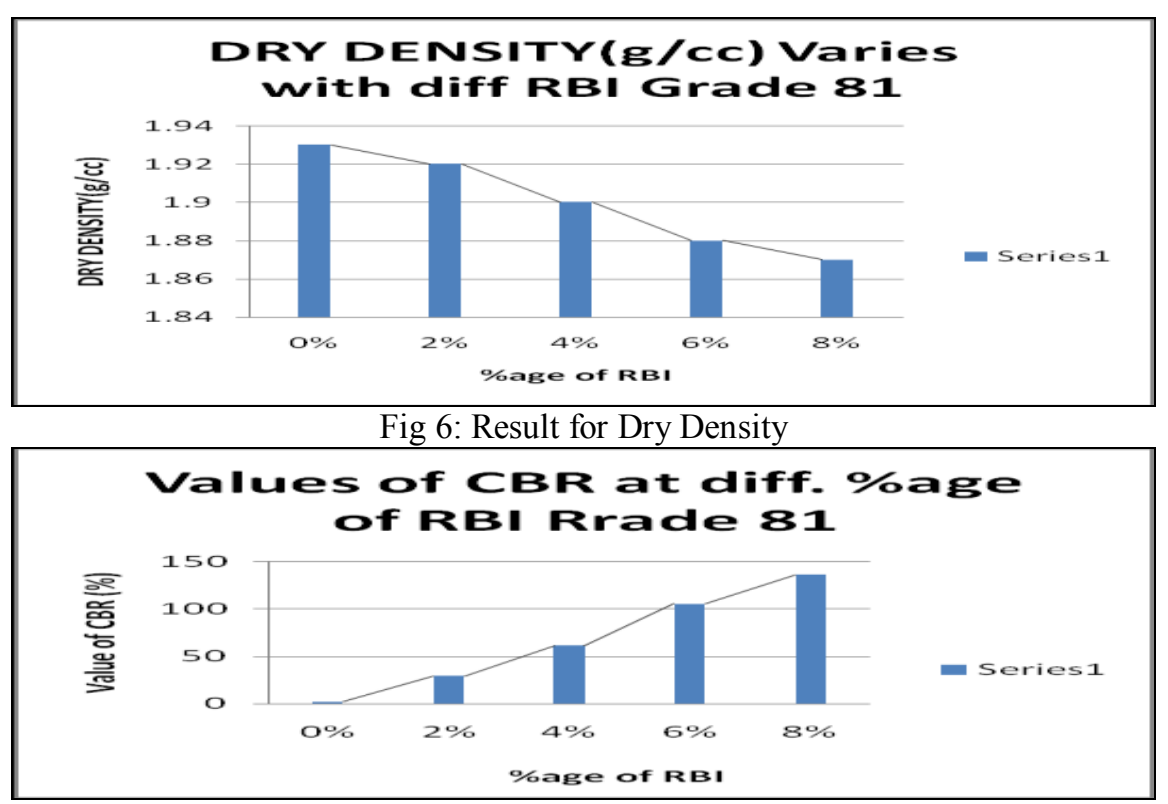

Fig 7: Values of CBR at diff. \%age of RBI Grade 81

\section{Optimization Of Flexible Pavement Design For Rural Road}

Various alternatives may be available to design a road section as per IRC specifications and MORT\&H Rural Road Specifications. The alternatives may be in terms of providing designed road crust on natural compacted sub grade or stabilized sub grade or stabilized soil as sub base for the use of local available materials like brick bats, sand, GSB, combination of one or more of the above. The cost of each section will vary depending upon the basic rate, transportation cost, mixing cost, growth rate, of traffic, compaction cost, soil characteristics, traffic intensity, rainfall, ground water table, particular site. Different design options need to be evaluated to find optimum pavement design applicable to the relevant location.

After doing testing on various samples, with the help of CBR design chart recommended by Indian Road Congress IRC: SP: 20: 2002 the Total thickness is found out to cover the sub grade for all samples.

It is assumed that there are 100 no. of commercial vehicles per day. So, curve $\mathrm{C}$ is used for obtaining thickness over sub grade. CBR curves for flexible pavements design (IRC: SP: 20-2002) is shown below.

Table 2: Thickness of pavement above sub grade from IRC: SP: 20-2002

\section{Cost Analysis}

Using the analysis of rates, the optimum pavement design can be evaluated. For comparison purpose, the common cost elements of embankment and sub grade material cost, compaction cost and pavement surfacing cost has not been included in the analysis.

\begin{tabular}{|c|c|c|}
\hline S.No & $\begin{array}{c}\text { \% AGE OF RBI } \\
\text { GRADE 81 }\end{array}$ & $\begin{array}{c}\text { COST IN } \\
\text { LACS. }\end{array}$ \\
\hline 1 & $0 \%$ & 2985418 \\
\hline 2 & $2 \%$ & 1400159 \\
\hline 3 & $4 \%$ & 1841159 \\
\hline 4 & $6 \%$ & 1816492 \\
\hline 5 & $8 \%$ & 2257492 \\
\hline \multicolumn{3}{|c|}{ Table 3: Cost of Pavement } \\
\hline
\end{tabular}

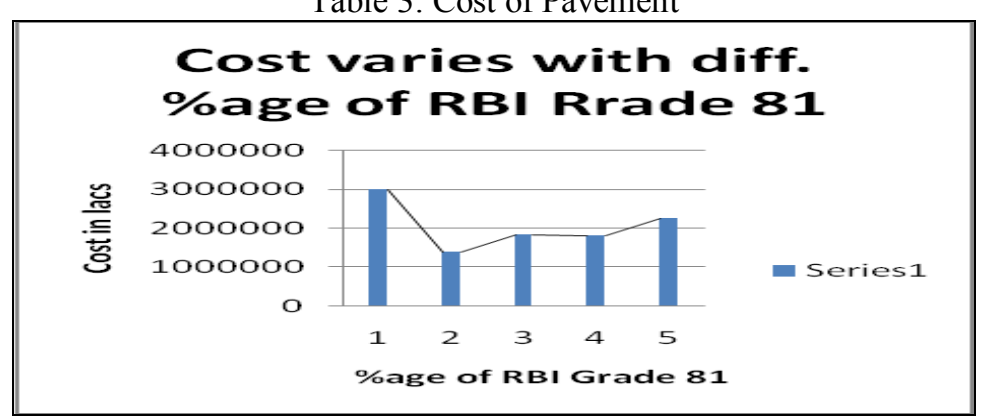

Fig 8: Cost of Pavement in Lacs 


\section{Conclusions}

This work was intended to study the effect of stabilizer RBI Grade 81 in the stabilization of soil. Based on results of Atterberg's limits; standard proctor test and CBR test the following conclusions are drawn. The conclusions are based on the tests carried out on samples selected for study. The conclusions drawn from the study are

1. Liquid limit decreased and Plastic limit increased with the addition of RBI Grade 81. Decrease in liquid limit and increase in plastic limit indicates increase in strength.

2. Highly plastic soil can be stabilized with RBI Grade 81 and can be considered as stabilized sub base. So RBI Grade 81 is a good stabilizer.

3. With the addition of RBI Grade 81 , PI decreased. The PI of soil is 9.4 which is reduced up to 4.7 with $8 \%$ of RBI Grade 81. Decrease in plasticity index shows that the volume change during wetting and drying with RBI Grade 81 is less.

4. OMC increased and MDD decreased with addition of RBI Grade 81. MDD is decreasing with addition of RBI Grade 81 but there is increase in soaked CBR value with increased the addition of RBI Grade 81. So strength does not decrease with decrease in MDD.

5. CBR increased with the addition of RBI Grade 81 . The CBR value of the existing soil was about $2 \%$, which has been increased to $28.9 \%$ by adding $2 \%$ RBI after 7 days of curing and 4 days of soaking. At $8 \%$ RBI 81 content CBR value is 135.5 this means RBI Grade 81 is very effective stabilizer.

6. The cost of Pavement for soil $+2 \%$ of RBI Grade 81 ; Shows minimum cost among all other cases. By conventional method cost of the pavement is Rs. 2985418/- which is too much higher than the cost of Pavement for soil $+2 \%$ of RBI Grade 81 .

\section{Acknowledgement}

The authors are grateful to Chandigarh University, Gharuan, Mohali-Punjab \& PEC, University of technology, Chandigarh \& for their cooperation and encouragement to carry out the work.

\section{References}

[1] Ajith, K., (1993), "Modification of Red Soil by Using Lime and Fly Ash as Admixtures", M.Tech Thesis, University of Kerala, Trivandrum.

[2] Gaulkar, M. P., (1999), "Construction of Roads in Black Cotton Soil”, Indian Highways, New Delhi.

[3] Biju, P. B., (2003), "Studies on Soil Stabilisation Using TerraZyme for Pavement Subgrade", M.Tech Thesis, University of Kerala, Trivandrum.

[4] Kunal Jain; (2006), “EVALUATION OF CEMENT STABILIZED SUGRADE.” M.Tech Thesis, Punjab Engineering College, University Of Technology, Chandigarh.

[5] Mithra Dewars; Satender Kumar \&Mohit Verma; (2009) "A Case Study On Rapid Pavement Construction by In-Situ Soil Stabilization" Legend Surface Developers Pvt. Ltd., New Delhi

[6] Venu Gopal.N; (2009), "Study Of Soil Properties With Silica fume As Stabilizer And Comparing The same With Rbi-81 And Cost Estimation" Post Graduate Diploma Thesis, Visvesvaraya Technological University, Belgaum.

[7] www.rbi81.com "RBI Grade 81 Natural Soil Stabilizer" accessed on 2008.

[8] IRC: SP: 20-2002 Recommended Design Criteria for rural road design.

[9] Highway Material Testing, lab manual by S.K. Khanna and C.E.G. Justo. 